Syntax Literate: Jurnal Ilmiah Indonesia p-ISSN: 2541-0849

e-ISSN : 2548-1398

Vol. 6, No. 7, Juli 2021

\title{
PENGELOLAAN DANA DESA MENUJU GOOD GOVERNMENT GOVERNANCE PADA DESA PASAR LAMA KABUPATEN BANJAR
}

\section{Agnia Medina Hastuty, Hero Priono}

Universitas Pembangunan Nasional (UPN) Veteran Jawa Timur, Indonesia

Email: agniania12@gmail.com, heropriono1161@gmail.com

\begin{abstract}
Abstrak
Penelitian ini bertujuan untuk mengetahui bagaimana Pengelolaan Dana Desa Menuju Good Government Governance Pada Desa Pasar Lama Kabupaten Banjar. Good Government Governance meliputi Partisipasi, Penegakan hukum, Akuntabilitas, Daya Tanggap, Berorientasi pada konsenus, Keadilan, Efisiensi dan Efektivitas, Visi strategis, dan Transparansi. Di masa pandemi Covid-19, 8\% dari dana desa dialokasikan untuk penanganan Covid-19, dengan adanya peraturan tersebut maka pnegalokasian dana desa akan berbeda dengan yang telah direncanakan. Metode penelitian yang digunakan adalah metode kualitatif dengan paradigma interpretif. Informan terdiri dari Penanggung Jawab Desa, Sekretaris Desa, dan Kepala Urusan Keuangan Desa Pasar Lama Kabupaten Banjar. Teknik pengumpulan data menggunakan wawancara dan dokumentasi. Teknik analisis data dimuai dari penyederhanaan data, proses mengecek keabsahan data, proses analisis data dan menarik kesimpulan. Hasil penelitian menunjukkan bahwa Pemerintah Desa Pasar Lama Kabupaten Banjar telah menerapkan prinsip Partisipasi, Daya Tanggap, Berorientasi ada Konsensus, Keadilan, Efisiensi dan Efektivitas, Visi Strategis, dan Transparansi dalam pengelolaan dana desa dengan baik. Tetapi belum sepenuhnya terlaksana di Prinsip Akuntabilitas karena kerap belum tepat waktu dalam menyajikan Laporan Keuangan dan juga belum melaksankaan SIJAKA atau Sistem Informasi Jaga Kawal. Pemerintah Desa Pasar Lama sudah cukup baik dalam pelaksanaan pengelolaan Dana Desa, tetapi diperlukan peningkatan dalam efektivitas waktu untuk menyajikan laporan keuangan dan menngunakan Sistem Informasi yang telah disediakan.
\end{abstract}

Kata Kunci: dana desa; pengelolaan dana desa; good government governance

\section{Abstract}

The purpose of this research was to know how management of village funds towards good government governance in Pasar Lama Village of Banjar Regency. Good Government Governance including Participation, Rule of Law, Accountabillity, Responsiveness, Consenses Orientation, Equity, Effectiveness and efficiency, Strategic vision, and Transparation. The research method used is qualitative with interpretive paradigm. The informant consist of the Village Person In Charge, Village Secretary, and the Head of Financial Affairs of Pasar Lama Village, Banjar Regency. Data collection techniques using interviews and documentation. Data analysis techniques are acquired from simplification of data,

$\begin{array}{ll}\text { How to cite: } & \begin{array}{l}\text { Hastuty, Medina Agnia., Hero Priono (2021) Pengelolaan Dana Desa Menuju Good Government } \\ \text { Governance Pada Desa Pasar Lama Kabupaten Banjar. Syntax Literate: Jurnal Ilmiah Indonesia 6(7). } \\ \text { http://dx.doi.org/10.36418/syntax-literate.v6i7.3502 }\end{array} \\ & 2548-1398 \\ \text { E-ISSN: } & \text { Ridwan Institute }\end{array}$


process of checking data validity, data analysis process and drawing conclusion. The result showed that the Government of Pasar Lama Village Banjar Regency has applied the principles of participation, Responsiveness, Consensus Orientation, Equity, Effectiveness and Efficiency, Strategis Vision, and Transparency in the management of village funds well. But it has not been fully implemented in Accountability Principle because it is often not on time in showed Financial Statements and also has not conducted the SIJAKA or Control Guard Information System. The government of Pasar Lama Village Banjar Regency has been quite good in the implementation of village fund management, but it takes an increase in the effectiveness of time to present financial statements and use the information system that has been provided.

Keywords: village funds; management of village funds; good government governance

\section{Pendahuluan}

Pemerintahan di Indonesia berkembang semakin pesat pada era reformasi dalam pelaksanaan desentralisasi dan otonomi daerah. Desentralisasi sebagai instrumen dengan membawa adanya pemerintah daerah dalam sebuah negara. Desentralisasi tersebut membentuk local self-government atau otonomi daerah. Undang-Undang No. 32 tahun 2004 pasal 1 ayat (5) menyebutkan bahwa "Otonomi daerah adalah hak, wewenang, dan kewajiban daerah otonom untuk mengatur dan mengurus sendiri urusan pemerintahan dan kepentingan masyarakat setempat sesuai dengan peraturan perundang-undangan" dalam kata lain Pemerintah daerah diberikan kewenangan penuh dalam pengelolaan daerahnya (Widianto, Harjanti, Utami, \& Sari, 2018).

Secara aktual, tujuan penyelenggaraan otonomi daerah yaitu untuk menjalankan otonomi yang seluas-luasnya yang bertujuan mempercepat terwujudnya kesejahteraan masyarakat (Maranjaya, 2018). Seiring dengan perkembangan semangat untuk berakselerasi sehingga terwujudnya kesejahteraan masyarakat melalui otonomi daerah kemudian dikembangkan di desa sistem otonomi melalui pemberlakuan UndangUndang Nomor 60 Tahun 2014 tentang Desa dan Pemerintah Peraturan No. 43 Tahun 2014 sebagai peraturan pelaksana (Supriadi, 2015).

Pada penelitian (Wayan Rustiarini, 2016) pengelolaan Dana Desa di Provinsi Bali secara normatif dapat dikatakan sesuai dengan mekanisme dalam UU No 6 Tahun 2004 tentang Desa dan Peraturan Pemerintah No. 60 Tahun 2014 Dana Desa yang Bersumber dari Anggaran Pendapatan dan Belanja Negara melalui APBD Kabupaten/Kota yang digunakan untuk membiayai administrasi, implementasi pembangunan, pengembangan masyarakat dan pemberdayaan.

Sejak tahun 2019, terjadi wabah Covid-19 yang mempengaruhi berbagai aspek. Salah satu dampak yang terjadi di desa termasuk dalam Pengelolaan Dana Desa. Menurut PMK Republik Indonesia Nomor 17/PMK.07/2021 tentang Pengelolaan Transfer ke Daerah dan Dana Desa Tahun Anggaran 2021 yang berisi dukungan penanganan pandemi, penyesuaian dukungan pendanaan yang dilakukan oleh Pemerintah Daerah sebagaimana dimaksud pada ayat (3) sesuai dengan kebutuhan Daerah dengan memperhatikan tingkat kasus Covid-19 yang telah didtetapkan oleh 
Badan Nasional Penanggulangan Bencana 3 bulan setalah Pemerintah Daerah menyediakan dukungan pendanaan paling sedikit sebesar 8\% (delapan persen) sebagaimana yang dimaksud pada ayat (1).

Penelitian ini dilakukan di Desa Pasar Lama, salah satu desa yang ada di Kecamatan Karang Intan Kabupaten Banjar. Sebagai salah satu desa di kabupaten Banjar, desa ini dituntut untuk mampu mengimplementasikan kesembilan dari prinsip GGG tersebut dalam pengelolaan dana desa yang terdapat dalam laporan keuangan desa. Penelitian ini membahas tentang pengelolaan dana desa menuju good government governance. Peneliti ingin melihat bagaimana pengelolaan dana desa menuju good government governance dengan menerapkan prinsip-prinsipnya. Oleh karena itu, peneliti tertarik untuk meneliti lebih lanjut persoalan Pengelolaan Dana Desa. Tujuan dari penelitian ini yaitu untuk mengetahui pengelolaan Dana Desa di Desa Pasar Lama. Diharapkan dari penelitian ini akan membuat masyarakat mengetahui tentang pengelolaan dana desa.

\section{A. Dana Desa}

Sumber dana desa adalah APBN melalui APBD yang dipergunakan guna mendanai penyelenggaraan pemerintah, pembangunan yang dilaksanakan, pembinaan, serta pemberdayaan masyarakat didasarkan pada Peraturan Pemerintah Nomor 43 Tahun 2014. Dengan begitu diperlukannya pelaporan keuangan di tingkat desa sebagai alat evauasi untuk melihat keuangan desa dikelola dan dijalankan efektif dan efisien (Savitri, Andreas, \& Diyanto, 2019).

\section{B. Pengelolaan Keuangan Desa}

Pengelolaan Keuangan Desa meliputi semua kegiatan dimulai dari perencanaanMenurut Peraturan Menteri Dalam Negeri Nomor 113 Tahun 2014 Tentang Pengelolaan Keuangan Desa meliputi seluruh kegiatan mulai dari perencanaan, pelaksanaan,penatausahaan, pelaporan, dan juga pertanggungjawaban keuangan desa (Syachbrani \& Yahya, 2018).

\section{Prinsip-prinsip Good Government Governance}

Terselenggaranya good government governance menjadi syarat dalam mewujudkan aspirasi masyarakat untuk mencapai tujuan berbangsa dan bernegara (Syahadatina, 2017). Menurut UNDP dalam (Mardiasmo, 2016) terdapat 9 prisip GGG yang dikembangkan, yaitu: partisipasi, penegakan hukum, akuntabilitas, daya tanggap, berorientasi pada konsensus, keadilan, efisiensi dan efektivitas, visi strategis, dan transparansi.

\section{Metode Penelitian}

Jenis penelitian yang digunakan pada penelitian ini yaitu kualitatif dengan paradigma interpretif yang berisi kata-kata tertulis ataupun lisan dari informan. Paradigma tersebut digunakan karena peneliti ingin memahami dan mempelajari fenomena yang akan diteliti, yaitu pengelolaan desa menuju good government governance (Cresswell, 2017). 
Lokasi yag dipilih oleh peneliti adalah Desa Pasar Lama, Kabupaten Banjar. Penelitian ini menetapkan informan berdasarkan pandangan bahwa informan dapat memberikan informasi yang penliti inginkan dan sesuai dengan permasalahan penelitian. Informan dalam penelitian ini adalah Penanggung Jawab (PJ) Desa Pasar Lama, Sekretaris Desa Pasar Lama dan Kepala Urusan Keuangan Desa Pasar Lama.

Jenis data yang digunakan dalam penelitian ini yaitu data primer yang diperoleh dari hasil wawancara langsung diberikan dari sumber data kepada pengumpul data (Sugiyono, 2017) yaitu Pejabat Desa Pasar Lama dan data sekunder diperoleh dari dokumen yang berkaitan dengan penelitian ini.

\section{Hasil dan Pembahasan}

Pengelolaan dana desa menuju Good Government Governance Pada Desa Pasar Lama di Pemerintahan Desa, pencatatan dilakukan dengan sistem keuangan desa (Siskeudes) digunakan untuk mengelola keuagan desa berupa Realisasi Anggaran dan APBDes yang digunakan untuk pembangunan desa. Sesuai dengan informasi dari Sekretaris Desa Pasar Lama (Ridwan, 2019):

"Pencatatan kita itu memakai sistem Siskuades, nah jadi pelaporannya itu langsung di aplikasi tapi kita dari desa print out nya kita ulahkan itu biasanya di akhir tahun kita ulahakan laporan pertanggungjawabannya (SPJ)."

Pengelolaan dana desa harus dilakukan sesuai dengan prinsip-prinsip Good Government Governance, menurut UNDP dalam (Mardiasmo, 2009) ada 9 prinsip dalam pelaksanaan good government governance yaitu, partisipasi, penegakan hukum, akuntabilitas, daya tanggap, berorientasi pada konsensus, keadilan, efisiensi dan efektivitas, visi strategis, dan transaparansi. Prinsip partisipasi terlihat di tahap perencanaan yaitu pemerintah desa yang selalu mengundang masyarakat untuk berpartisipasi dalam Musrembangdes. Sesuai dengan pernyataan dari sekretaris desa Pasar Lama:

"Pengambilan keputusan terlibat, terlibatnya dalam perencanaan tadi apa aja kegiatan tahun yang mau prioritaskan nah itu tadi hasil kesepakatan masyarakat tadi lalu kita menyepakai beberapa kegiatan yang kita prioritaskan dulu."

Prinsip Penegakan hukum (rule of law) yang dilakukan demi terwujudnya demokratisasi kehidupan dalam berbangsa dan bernegara (Ansori, 2018). Dengan menaati peraturan yang ada termasuk dalam melaksanakan tata kelola pemerintahan yang baik. Di Desa Pasar Lama telah mengelola Dana Desa sesuai dengan peraturan yang berlaku, sesuai dengan informasi yang diberikan oleh PJ Desa Pasar Lama:

"Kita harus melaksanakan dana tersebut melalui keputusan keputusan yang diberikan oleh atasan kita, dana desa tersebut misal diberikan kepada BLT. Di BLT tersebut ada surat dari Bupati jadi kita tidak bisa mengusulkan ini itu tapi bertentangan dengan perbub, jadi harus melaksanakan sesuai dengan peratuarn bupati yang diberikan kepada desa." 
Akuntabilitas merupakan salah satu unsur penting dari good government governance mengenai kemampuan pemerintah desa dalam mempertanggungjawabkan kegiatan yang akan dilaksanakan. Setiap desa diharuskan mengelola Dana Desa dengan akuntabel sehingga meminimalisir adanya penyalahgunaan (Savitri et al., 2019). Di Desa Pasar Lama telah menerapkan prinsip Akuntabilitas namun belum sepenuhnya terlaksana karena dalam menyajikan laporan keuangannya belum tepat waktu, kemudian belum terlaksananya Sistem Informasi Jaga Kawal (SIJAKA), yaitu aplikasi yang digunakan untuk pengawasan kegiatan di Desa.

"Sudah sesuai, cuma masih ada yang belum kita laksanakan "SIJAKA" buat pengawasan pengelolaan dana desa dan juga kadang dalam penyajian laporan keuangannnya balum tepat waktu."

Dalam undang-undang pelayanan publik Nomor 25 Tahun 2009 pasal 27 ayat (1) menyatakan bahwa penyelenggaraan berkewajiban untuk menyusun dan menetapkan standar pelayanan dengan memperhatikan kemampuan penyelenggara, kebutuhan masyarakat, dan kondisi lingkungan. Pemerintah Daerah diharapkan responsif terhadap kebutuhan masyarakat, sesuai dengan pernyataan dari PJ Desa Pasar Lama sebagai berikut:

"Selama ini responsif aja, cuman terkendalanya itu terbatasnya dana, jadi oleh karena terbatasnya dana jadi kita memilah milah apa yang lebih dominan yang akan didahulukan. Kalau masyarakat itu kan semua handak didahulukan semuanya inginnya dibiayai kalaunya bisa harus tahun ini. Tapi kalau kita dibatasi oleh dana maka tadi kita melaksanakan kegiatan-kegiatan yang namanya musrembang, jadi mereka sadar diri lah bahwa dana kita terbatas."

Tata pemerintahan yang baik dan berorientasi pada konsensus berpijak pada keputusan-keputusan yang diambil antara lembaga eksekutif dan legislatif harus didasarkan pada konsensus agar setiap kebijakan publik yang diambil benar-benar merupakan keputusan bersama. Keterlibatan Pemerintah Desa dengan masyarakat dalam rangka merencanakan APBDes. Setelah diadakannya musyawarah, rencana tersebut akan disetujui oleh BPD. Seuai informasi oleh PJ Desa Pasar Lama:

"Kalaunya BPD itu sebagai mitra kepala desa mitra aparat desa, jadi apa yang akan kita laksanakan itu kita musyawarahkan terutama mengenai BPD. Kalaunya BPD tidak setuju kita mundur. Tapi jarang juga ada tidak setuju, kemungkinan ada beberapa hal yang tidak setuju namun salah pengertian saja mereka. Kalau di desa pasar lama baik-baik aja karena ketika ada kegiatan kita tidak pernah meninggalkan BPD selalu kita bawa rapat 2 di desa itu, dan dalam rapat tersebut kita ada bukti bahwa kita melaksankan kegiatan rapat-rapat tersebut dengan BPD yaitu dengan daftar hadir saat musyawarah tersebut."

Dalam Permendagri No. 113 tahun 2014 tentang pengelolaan keuangan desa, APBDes disusun melalui Musrembangdes yang dihadiri aparat desa dan masyarakat mengacu bahwa APBDes yang sudah direncanakan dapat terealisasikan pembangunannya secara merata (Syahadatina, 2017). Masyarakat yang hadir dalam 
Musrembangdes mempunyai hak yang sama dalam mengemukakan pendapatnya. Sesuai dengan pernyataan dari PJ Desa Pasar Lama, yaitu:

"Iya, masyarakat ada kesempatan yang sama dalam melaksanakan musrembangdes. Musrembandes ini kan per RT. Mengajukan keinginan ini itu kita tampung dari semua RT. Lalu per RT itu kita cari yang mana yang harus didahulukan, kita catat yang keperluannya lebih dari 10 atau lebih, yang mana yang priorotas. Jadi yang prioritas itu di tahun mendatang akan dilaksanakan tapi bertahap untuk yang lainnya."

Efisiensi dan efektivitas dalam hal pelayanan publik dinilai bagus jika masyarakat mendapat kemudahan pelayanan dengan memuaskan. Dalam segi fasilitas, pelayanan publik yang dilakukan harus dibuat seefektif dan seefisien mungkin. Sesuai informasi yang diberikan oleh Sekretaris Desa:

"Kalo fasilitas kita langsung di kantor desa aja. Di internet (website) pernah, tapi masyarakat kurang membuka disitu jadinya kita harus menggunakan banner ataupun papan pengumuman."

Dalam era sekarang setiap desa harus memiliki visi strategis agar tidak mengalami ketertinggalan. Seperti di Desa Pasar Lama, ada pembuatan visi yang dilihat dari situasi dan kondisi Desa sekarang dan dilihat potensi untuk kedepannya. Sesuai yang dijelaskan oleh PJ Desa Pasar Lama, yaitu:

"Ada, di desa pasar lama. Itu kita harus melihat sikonnya untuk melaksanakan dalam membuat visi tersebut. Kalau visi tersebut kita harus mewujudkan pelayanan yang maksimal kepada masyarakat, kemudian untuk memaksimalkan pembangunan di masyarakat. Baik pembangunan gedung-gedung, atau fisik maupun mental. Jadi kalau visi misi itu dibuat oleh kepala desa yang definitif sedangkan kita ini pembakan pejabat. Pejabat sementara belum ada pemilihan dilaksankan dan pelantikan oleh sebab itu kami melaksankaan visi misi pembakal yang telah lalu. Oleh sebab itu sampai saat ini belum terlaksana pemilihan. Dikarenakan yang pertama kita dapat musibah wabah covid, yang kedua musibah banjir. Oleh sebab itu kita b elum ada pemilihan, tapi InshaAllah habis puasa lebaran ini kita melaksnakan pemilihan. Kemarin sudah beberapa kali bapak Bupati melaksanakan rapat untuk pemilihan."

Adanya transparansi dalam pengelolaan desa menjadikan masyarakat lebih mengetahui bagaimana pengelolaan Dana Desa. Permendagri no 37 tahun 2007 tentang Pedoman Pengelolaan Keuangan Daerah pada pasal 4 ayat 7 menyebutkan bahwa transparansi merupakan prinsip keterbukaan yang memungkinkan masyarakat untuk mengetahui dan mendapatkan akses informasi yang luas tentang keuangan daerah. Dana desa yang dialokasikan ke berbagai kegiatan harus diketahui oleh masyarakat, bisa secara langsung maupun tertulis seperti pemasangan banner. Sesuai dengan hasil wawancara dengan Sekretaris Desa Pasar Lama, yaitu: 
"Iya, kita laksanakan tiap tahun. Melalui kita memasang banner APBDes di depan kantor dan di tempat-tempat strategis lainnya dan juga kita melakukan sosialisai di tiap-tiap rapat kita sampaikan apa aja kegiatan tahun ini."

Tabel 1 hasil analisis dari prinsip Good Government Governance:

\begin{tabular}{|c|c|c|c|}
\hline No & $\begin{array}{l}\text { Prinsip Good } \\
\text { Government } \\
\text { Governance }\end{array}$ & $\begin{array}{c}\text { Analisis } \\
\text { (Sudah } \\
\text { Terlaksana/Belum } \\
\text { Sepenuhnya) }\end{array}$ & Alasan \\
\hline 1 & Partisipasi & Sudah Terlaksana & $\begin{array}{l}\text { 1. Masyarakat telah berpartisipasi dan } \\
\text { berperan aktif dalam menyampaikan } \\
\text { aspirasi di kegiatan musrembangdes. }\end{array}$ \\
\hline 2 & Penegakan Hukum & Sudah Terlaksana & $\begin{array}{l}\text { 1. Di Desa Pasar Lama telah mengelola } \\
\text { Dana Desa sesuai dengan peraturan } \\
\text { yang berlaku. }\end{array}$ \\
\hline 3 & Akuntabilitas & Belum Sepenuhnya & $\begin{array}{l}\text { 1. Penyajian Laporan Keuangan belum } \\
\text { tepat waktu. } \\
\text { 2. Belum terlaksananya SIJAKA. }\end{array}$ \\
\hline 4 & Daya tanggap & Sudah Terlaksana & $\begin{array}{l}\text { 1. Responsif terhadap kepentingan } \\
\text { masyarakat } \\
\text { 2. memprioritaskan masyarakat }\end{array}$ \\
\hline 5 & $\begin{array}{l}\text { Berorientasi pada } \\
\text { konsenus }\end{array}$ & Sudah Terlaksana & $\begin{array}{l}\text { 1. Pemerintah Desa sebagai penegah } \\
\text { antara masyarakat desa }\end{array}$ \\
\hline 6 & Keadilan & Sudah Terla ksana & $\begin{array}{l}\text { 1. Adanya Musyawarah Desa } \\
\text { 2. Masyarakat mendapat kesempatan } \\
\text { yang sama untuk mengemukakan } \\
\text { pendapat }\end{array}$ \\
\hline 7 & $\begin{array}{l}\text { Efisiensi } \\
\text { Efektivitas }\end{array}$ & Sudah Terlaksana & $\begin{array}{l}\text { 1. Adanya kantor desa sebagai pusat } \\
\text { pelayanan publik }\end{array}$ \\
\hline 8 & Visi strategis & Sudah Terlaksana & $\begin{array}{l}\text { 1. Selalu lihat situasi dan kondisi dalam } \\
\text { pembuatan visi yang bertujuan } \\
\text { memajukan kesejahteraan masyarakat. }\end{array}$ \\
\hline 9 & Transparansi & Sudah Terlaksana & $\begin{array}{l}\text { 1. Sudah secara transparan } \\
\text { menginformasikan kepada masyarakat }\end{array}$ \\
\hline
\end{tabular}

Sumber: Data Diolah

\section{Kesimpulan}

Pengelolaan Dana Desa yang ada di Desa Pasar Lama sudah dilaksanakan sepenuhnya sesuai dengan prinsip-prinsip Good Government Governance yaitu Partisipasi, Daya Tanggap, Berorientasi pada konsensus, Keadilan, Efisiensi dan Efektivitas, Visi Strategis, dan juga Transparansi. Namun, ada beberapa prinsip yang belum sepenuhnya terlaksana yaitu Akuntabilitas.

Dari data di atas, dapat disimpulkan bahwa Desa Pasar Lama dilihat dari pengelolaan Dana Desa dengan baik dan dimasa pandemi telah sesuai dengan PMK Republik Indonesia Nomor 17/PMK.07/2021 yaitu adanya dukungan pendanaan paling sedikit $8 \%$ dalam rangka penanganan pandemi. Jika dikaitkan dengan hakikat pertanggungjawaban maka masih terdapat beberapa kelemahan yaitu belum tepat waktu 
Pengelolaan Dana Desa Menuju Good Government Governance pada Desa Pasar Lama

Kabupaten Banjar

dalam penyajian laporan keuangan dan juga belum melaksanakan Sistem Informasi Jaga Kawal. 


\section{BIBLIOGRAFI}

Ansori, Lutfil. (2018). Reformasi Penegakan Hukum Perspektif Hukum Progresif. Jurnal Yuridis, 4(2), 148-163. Google Scholar

Cresswell, J. W. (2017). Research Design: Pendekatan Kualitatif, Kuantitatif, dan Mixed (Edisi Ketiga). Yogyakarta: Pustaka Belajar. Google Scholar

Maranjaya, Abdul Kahar. (2018). Kebijakan Daerah Sebagai Landasan Pelaksanaan Otonomi Daerah. Al-Qisth Law Review, 1(2), 14. Google Scholar

Mardiasmo. (2009). Akuntansi Sektor Publik. Yogyakarta: CV. Andi.

Mardiasmo. (2016). Perpajakan. Yogyakarta: CV. Andi.

Ridwan, Muhammad Anur. (2019). Analisis Peran Aplikasi Sistem Keuangan Desa (SISKEUDES) Dalam Meningkatkan Kualitas Akuntabilitas Keuangan Desa Di Tinjau Dari Perspektif Ekonomi Islam (Studi Pada Desa Bogorejo, Kecamatan Gedong Tataan, Kabupaten Pesawaran. UIN Raden Intan Lampung. Google Scholar

Savitri, Enni, Andreas, Andreas, \& Diyanto, Volta. (2019). Accountability Of Village Funds Management. Jurnal Aplikasi Manajemen, 17(3), 515-521. Google Scholar

Sugiyono, P. D. (2017). Metode Penelitian Bisnis: Pendekatan Kuantitatif, Kualitatif, Kombinasi, dan R\&D. Penerbit CV. Alfabeta: Bandung. Google Scholar

Supriadi, Edy. (2015). Pertanggungjawaban kepala desa dalam pengelolaan keuangan desa berdasarkan undang-undang nomor 6 tahun 2014 tentang desa. Jurnal IUS Kajian Hukum Dan Keadilan, 3(2). Google Scholar

Syachbrani, Warka, \& Yahya, Muhammad. (2018). Realisasi Perencanaan Dan Pelaksanaan Tata Kelola Keuangan Pemerintah Desa. Bongaya Journal for Research in Management (BJRM), 1(2), 45-55. Google Scholar

Syahadatina, Rika. (2017). Akuntabilitas Pengelolaan Alokasi Dana Desa di Desa Rapa Laok Kecamatan Omben Kabupaten Sampang. Jurnal Akuntansi Dan Investasi, 2(1), 1-18. Google Scholar

Wayan Rustiarini, Ni. (2016). Good Governance dalam Pengelolaan Dana Desa Simposium Nasional Akuntansi XIX. (October), 1-18.

Widianto, Andri, Harjanti, Ririh Sri, Utami, Erni Unggul Sedya, \& Sari, Yeni Priatna. (2018). Akuntabilitas Pengelolaan Alokasi Dana Desa sebagai Instrumen Mewujudkan Good Governance (Studi Kasus di Kecamatn Brebes). Politeknik Negeri Jakarta, 5(2), 849-857. Google Scholar 


\section{Copyright holder:}

Agnia Medina Hastuty, Hero Priono (2021)

First publication right:

Syntax Literate: Jurnal Ilmiah Indonesia

This article is licensed under:

(c) (i) (? 